\title{
Some Effects of Deception and Level of Self-Monitoring on Planning and Reacting to a Self-Presentation
}

\author{
Gregory C. Elliott \\ Department of Sociology \\ University of Maryland
}

\begin{abstract}
This experiment addressed issues in impression management. First, this study investigated whether type of impression intended (accurate or fabricated) and level of self-monitoring (high or low) affect the amount of information about a target person that individuals would acquire, at some cost to themselves, prior to interacting with that person. As predicted, high self-monitors planning a fabrication purchased more information than high self-monitors planning an accurate impression or low self-monitors planning either type of impression. In addition, reactions of both participants to the actor's performance were analyzed. Impression type affected both actors' and targets' reactions, whereas self-monitoring affected only the targets' ratings.
\end{abstract}

Erving Goffman, in his seminal work on impression management (1959), has discussed how individuals present an impression of self that influences the definition of the situation that others come to formulate. It is in the various parties' best interest to induce others to attribute qualities to them that are supportive of their own interaction goals. People can do this by expressing themselves in a manner that communicates impressions intended to lead others to support their plans voluntarily. The current experiment focuses on actors' preparation for an upcoming encounter and reactions to their performance.

The experiment reported herein was conducted as part of a doctoral dissertation for the Department of Sociology, University of Wisconsin, Madison. The research was supported by National Institute for General Medical Science Grant GM-01526-11 and by the Small Grants Committee, Department of Sociology, University of Wisconsin.

Special thanks are due Shalom H. Schwartz and Elizabeth E. DeCourcy-Wernette for their patient counsel and constructive criticism. I also thank $\mathrm{H}$. Andrew Michener, William Ickes, Jane Piliavin, Mark Snyder, John Fleishman, and the anonymous reviewers for their comments on earlier drafts.

Requests for reprints should be sent to Gregory C. Elliott, Department of Sociology, University of Maryland, College Park, Maryland 20742.

\section{Acquiring Information}

Actors planning for an interaction can benefit from information about the other participants. They can use this information to help them tailor their impression to fit the particular characteristics of the encounter. In considering the problems of creating and sustaining an impression, one should distinguish between impressions that the actor believes to be accurate self-presentations and impressions that the actor knows are false (fabrications, in Goffman's, 1959, terms). Information about others is helpful in conveying an accurate impression (if only to ensure accuracy), but it is even more important in conveying a fabrication. Whereas an accurate impression can be generated from habit and previous experience, actors planning a fabrication must be wary of the possibility of being discredited. Behavior must be carefully monitored and, when necessary, accentuated or suppressed. Normal, habitual behavior that usually enhances an accurately descriptive performance could betray deceiving actors. Fabricators must be sensitive to elements of the encounter that could threaten or enhance their performance. In particular, information about the other participants in the interaction can indicate the kind of performance most likely to succeed. 
There is evidence that individuals differ in the importance they attach to information about other participants. Snyder's (1974, 1978 , in press) work on self-monitoring tendencies indicates that some individuals show a greater attentiveness to external cues (i.e., information from the environment in which an interaction occurs) when judging the appropriateness of an impression and the effectiveness of a performance. Labeled high selfmonitors, they are concerned with the situational appropriateness of their behavior during a social encounter. As a result, they show greater sensitivity to the characteristics of others involved in the interaction, whether revealed by self-presentation or by inadvertence.

On the other hand, low self-monitors do not rely so much on social comparison information. Although they may also be concerned with their behavior in an encounter, they tend to rely on internal cues (such as internalized norms or attitudes) to guide their self-presentation.

It follows that high self-monitors should be eager to acquire information about other participants in the interaction. This should be especially true if they plan to convey a fabrication. The challenge of having to contradict their own attitudes or beliefs without revealing the contradiction makes them more careful than usual about their performance. This greater care manifests itself in part in an increased interest in information about other participants. Actors can use relevant information about others to plan their fabrication more precisely and to increase the likelihood of success.

On the other hand, individuals attentive to internal cues (low self-monitors) should feel little need for information about other participants, regardless of the type of impression to be conveyed. Their behavior is guided by their own beliefs about what is necessary to convey the intended impression, be it accurate or fabricated. Although they may feel increased concern in planning a fabrication, it is manifested in a more thorough introspection for guides to action, not in a need for information about others.

Prior research on the acquisition of infor- mation about other participants in an upcoming interaction is sparse. Snyder (1974) found that, compared to low self-monitoring subjects, high self-monitors spent more time looking at a sheet of majority responses to a personality inventory that they were filling out while preparing for an upcoming discussion. This information was obtainable merely by turning one's head to see the majority response sheet taped to the wall near the subjects.

Note that this activity involved no real effort on the subjects' part, because the information was readily available. Information more critical to the actor may be more difficult to obtain and may involve some cost. Two studies (Eiser \& Eiser, 1976; Eiser \& Tajfel, 1972) investigated subjects' preferences for different kinds of information about an opponent in upcoming bargaining sessions. Subjects could find out how much each potential outcome would cost the opponent in resources expended and how much the outcome was valued in terms of resources gained. Each piece of information was available at a set price. Subjects purchased more information about the values the opponents placed on outcomes than on the costs; this value-cost difference was larger in competitive than in noncompetitive groups.

These studies indicate that individuals who expect to interact with another do seek out information about them. Although the bargaining experiments do not explicitly involve impression management, self-presentational concerns could be one aspect determining subjects' behavior. The present experiment investigated the acquisition of information by individuals prior to conveying a specific impression of themselves to another person. It differs from Snyder (1974) in that the information was available only at some cost to the actors. Unlike the studies conducted by Eiser and associates (Eiser \& Eiser, 1976; Eiser \& Tajfel, 1972), the present study investigates information purchasing in an explicit context of impression management.

The arguments presented above lead to the following hypotheses. First, because of their greater sensitivity to external cues for appropriateness of behavior in everyday en- 
counters, high self-monitors will seek out more information about another participant, even at some personal cost, than will low self-monitors. Second, the type of impression planned should influence the magnitude of the discrepancy between the information acquired by high and low self-monitors. A planned fabrication increases one's concern for performance during a self-presentation, which is reflected in a greater attentiveness to cues of situational appropriateness. For low self-monitors, this means more attention is paid to internal states, such as norms or personality characteristics, than would occur when planning an accurate impression. High self-monitors, by contrast, would be led to a greater reliance on information from the environment than would be required for an accurate performance. A two-way interaction between self-monitoring and impression type is therefore predicted: Prior to an accurate performance, high selfmonitors should acquire more information about another than will low self-monitors, but the difference in the amount acquired should be even greater when planning a fabrication.

\section{Reacting to the Encounter}

This study also investigated the participants' reactions to the encounter. Actors could conceivably react to their behavior during the interaction on two distinct levels: their own personal feelings during the encounter (were they comfortable, confident, self-conscious?) and their feelings about the performance they have just completed (were they successful, organized, persuasive?). Individuals may be able to separate critiques of their own performance quality from the feelings they had while performing, although the two are not necessarily independent. In addition, other participants in the interaction should be able to make judgments about the actor on the same dimensions of performance quality and apparent feelings.

In prior research, Ickes and Barnes (1977) found that when high self-monitoring subjects were paired with self-monitoring partners in an informal interaction, high self-monitors rated themselves and their partners as more self-conscious than did low self-monitors. Re- garding others' impressions of an actor's performance, Weiler and Weinstein (1972) discovered that accurate impression managers were judged more convincing than were fabricators.

Individuals conveying an accurate impression should feel little stress during the interaction. They have only to be themselves to keep the interaction proceeding smoothly. Fabricators, however, are under much more stress. They must constantly be alert for signals that their performance is being discredited. This leads to the hypothesis that actors who have just conveyed a fabrication will reveal more negative feelings about themselves and their performance than will those who have conveyed an accurate impression. Similarly, observers will evaluate the fabricating actors' performance more negatively than that of accurate impression managers, largely because of nonverbal leakage (Ekman \& Friesen, 1969).

High self-monitors check their performance during an interaction by judging the others' reactions to them and tailoring their selfpresentation accordingly; low self-monitors do not make much use of the reactions of others. Because high self-monitors are especially aware of the reactions of others, they are more critical of their performance than are low self-monitors. The hypothesis is that they will react more negatively than will low selfmonitors. On the other hand, greater attentiveness to reactions of others spurs the high self-monitors to correct any problems in their performance quickly. As a result, the hypothesis is that observers will evaluate the performance of high self-monitors more positively than that of low self-monitors.

\section{Method}

\section{Overview}

Subjects were led to believe that they were participating in a study of impression formation. They were asked to help the experimenter discover how people build impressions of others by conveying a specific impression about themselves to a target person (ostensibly a naive subject, but actually a confederate). This impression was either in harmony with their own attitude (accurate impression condition) or contrary to it (fabricated impression condi- 
tion). Subjects were told that the experimenter would be studying how the target person built an impression of them and what elements of the impression were important in the target person's mind.

A successfully formed impression would net both participants a monetary bonus. Before beginning the encounter, subjects were given the opportunity to purchase information about the target person by giving up some of the standard subject fee. After some time to prepare themselves, subjects spent 10 minutes in an informal face-to-face discussion with the confederate. Subjects and confederates then completed a questionnaire on which they rated the subjects' performance and feelings during the encounter.

\section{Subjects}

Sixty-six female students at a large Midwestern university served as subjects. All subjects had previously filled out preexperimental questionnaires. Two subjects were dropped from the analysis. One did not understand the instructions. A second refused in advance to be paid for her participation, commenting that this meant the information made available to her would cost her nothing. Since her orientation to the experiment was affected by her refusal to be paid, her responses were not comparable to the others.

\section{Preexperimental Questionnaire}

Six weeks before the experiment began, students from introductory sociology and education courses at the university filled out a preexperimental questionnaire. The questionnaire contained Snyder's (1974) Self-Monitoring Scale (labeled "personal reaction inventory") and a "critical issues inventory" that measured attitudes toward controversial issues. Two items on legalizing marijuana served as the basis for determining the accuracy of the impression to be conveyed. The items were scored from -3 (extremely unfavorable to legalization) to 3 (extremely favorable to legalization). Subjects receiving a summed score of 4 or more on these items were judged as definitely in favor of legalization and were eligible to participate in the experiment.

\section{Design}

The study utilized a $2 \times 2$ factorial design that varied type of impression (accurate vs. fabricated) and level of self-monitoring (high vs. low). The impression was accurate if the subject was asked to appear in favor of legalization; it was fabricated if the subject was asked to appear opposed to legalization. Subjects were high in self-monitoring if they scored above the median (12 in a possible range from 0 to 25 ) on the self-monitoring scale; they were low in self-monitoring if they scored below the median. Subjects were randomly assigned to the impressiontype condition, with the constraint that in each condition half the subjects must be high and half must be low in self-monitoring. This yielded 16 subjects in each cell of the design. Confederates were randomly assigned to each condition.

\section{Experimental Procedure}

In a preparation room, the experimenter explained the (fictitious) nature of the study. The confederates were not present. The experimenter explained that this experiment was an attempt to discover how people form an impression about another when they are face-to-face with that person, and that the subjects would serve as a discussion partner with another woman. They were also told that the experimenter would find out if the other woman had formed specific impressions about the subject after the discussion had ended. Subjects were told they would be paid $\$ 2.50$ for their participation. They then signed the participation consent form.

Next, the experimenter handed two instruction sheets to the subjects. The first described their task in general. Reading from the instructions, the experimenter explained that to ensure comparability across settings, the subjects' task was to convey a specific impression about themselves to their partner during a 10-minute, face-to-face conversation period. The specific impression dealt with marijuana legalization. The experimenter explained that he was interested in determining whether appearing to be for or against an issue influences how others build up an impression of people. Therefore, some would be randomly chosen to convey the impresson that they were in favor of legalizing marijuana use, whereas others would be randomly selected to appear opposed to it.

In addition, the experimenter told the subjects he was interested in whether the other person could build up an overall favorable picture of them at the same time she was learning whether they were for or against marijuana use. Subjects were asked to induce the other woman to like them, regardless of which side of the issue they were assigned. The purpose of this task was to keep the subject from merely stating her assigned views perfunctorily and to promote a more realistic conversation.

The experimenter explained that the other woman was the focus of the experiment. He said he would be analyzing exactly how she received the impression they would convey. The other woman (ostensibly) was with a (nonexistent) research assistant and had been told the study involved an analysis of what goes on in an informal, videotaped discussion of issues that affect college students' lives. The rationale for the 10-minute discussion was that it was a practice session to give the participants a chance to get used to the discussion.

Subjects were led to believe that the other woman had been given a list of possible discussion topics, including marijuana legalization. Since it was only one of several issues on the list, the subjects were told that they would probably have to bring up the topic themselves. They were told to do this in the manner most comfortable for them, as long as the 
partner had a fair chance to build an impression of how they felt about marijuana.

The experimenter stressed that it was important that the partner not realize that the study was really about impression formation until it was actually over; otherwise, she might try too hard and do things she wouldn't do in normal, everyday life.

The second instruction sheet informed the subjects of some special considerations regarding their task. First, the experimenter was interested in more than whether their partner came to understand how they felt about legalization. Subjects were asked to build up in the other person's mind an organized, sensible set of reasons supporting their position. To help them, they would have available a list of some of the most common reasons given for the position they were assigned to convey. The experimenter emphasized that their use of this list was entirely a matter for them to decide and that the quality of reasons used was at least as important as the quantity.

Second, subjects did not have to persuade the other person to agree with them. The experimenter was only interested in whether and how the partner came to understand what the subjects' position was.

Third, the subjects were told that success in forming impressions often carries some kind of benefit for those involved in the get-together. To simulate the real-life possibility of rewards, the subject and her partner would each earn a $50 \&$ bonus if the other woman formed both a clear impression of the subject's attitude toward marijuana legalization and an overall favorable impression of her. Success would be determined by the target person's responses to a questionnaire after the discussion.

Subjects were then taken to their separate interaction rooms, where the actual discussions were to take place. At this point, half the subjects learned that they were to convey the impression that they favored legalizing marijuana (an accurate impression), and the other half were to appear to oppose legalization (a fabricated impression). They were also given a list of 16 reasons supporting the assigned position. To this point, the experimenter had not known to which condition the subjects would be assigned. Throughout the study, the experimenter was blind to subjects' self-monitoring scores.

\section{Dependent Variable}

After considering their positions for a few minutes, subjects were given an opportunity to purchase information about their partner. Three kinds of information were available: biographical (e.g., hometown, religious preference), attitudinal (involving issues other than marijuana, e.g., abortion, the priority of conscience over law), and personality characteristics (e.g., assertiveness, tolerance for others). This information came from a self-descriptive questionnaire ostensibly being filled out by the other woman at that time. Actually, a standard response for each item was provided by the experimenter. These responses were neither extreme, in the case of the attitudinal and per- sonality items, nor unusual, in the case of the background information.

For every 2 bits of information selected, $1 \propto$ was deducted from the standard subject fee of $\$ 2.50$. Ten bits of each type were available (a total of 30 bits), for a maximum possible cost of $15 \%$. Subjects were told that the cost was to simulate the real-life possibility that one could often find out about another only at some cost to the self. The experimenter emphasized that subjects were free not to purchase any information at all. They could have as little or as much as they wanted. Subjects were given a few minutes alone to decide, at which time the experimenter returned with the questionnaire (presumably filled out by the other person) and filled in any requested responses. The amount and kind of information bought by the subjects constituted the major dependent variable.

\section{Performance Ratings}

After being given 5 minutes to prepare, subjects engaged in an informal 10-minute discussion with the partner, who was brought to the subjects' room. The other woman was actually a confederate, chosen for her ability at improvisational drama. ${ }^{2}$ She was trained to be easygoing, personable, and ambivalent regarding legalization. Although keeping up her end of the conversation, she did not direct nor dominate the conversation in any way. The confederates were blind to the impression-type manipulation and the premeasured attitudes of the subjects, as well as to the experimental hypotheses. Subjects were randomly assigned to a confederate.

Following the discussion, the subject and the other woman were separated, and each filled out the same questionnaire consisting of 30 bipolar adjectives in semantic differential form. Half of the items measured their impressions of the performance that the subject had just given (e.g., interesting, impressive); the rest measured their impression of what the subject had been feeling during the discussion. (e.g., enthusiastic, self-conscious). These items constituted the measure of the second dependent variable.

At this juncture, the subjects were extensively debriefed. This involved assessing their suspicion level, discovering their perceptions about the experiment, revealing the true nature of the experiment, and ensuring that they felt comfortable about their participation. The experimenter then paid the subjects $\$ 2.50$, cautioned them not to discuss the experiment, and dismissed them.

1 The reasons were generated from two sources: Kaplan (1970) and the National Commission on Marijuana and Drug Abuse (1972).

2 I thank Joyce Bizub, Mary Erdman, Laurie Franklin, Jane Homburg, Laura Raffe, and Dana Schwindt for serving as confederates. Their skill at improvisation added greatly to the believability of this experiment. 


\section{Results and Discussion}

\section{Internal Validity}

During the debriefing, the degree of suspicion the subjects expressed was coded. Complete surprise upon learning the true nature of the experiment was assigned a value of 0 ; some vague feeling that something else was going on was assigned 1 ; the correct inference that the subjects themselves were at least part of the focus of the study received a 2 ; guessing in addition that the partner was a confederate received a 3 ; correctly discerning that the experiment investigated the subject's impression management behavior was scored 4.

Complete surprise was expressed by $60.9 \%$ of the subjects, and $26.6 \%$ had only a vague feeling that something else was going on. The mean level of suspicion was .61, indicating that most subjects believed the cover story they were given. Analysis of variance in suspicion using level of self-monitoring and impression type as factors revealed that no condition caused more suspicion than any other. In addition, dichotomizing subjects into nonsuspicious (those receiving a coded value of 0 ) and suspicious (those receiving any other score) created a factor that showed no main effects on the dependent variables, nor were any interactions between suspicion and the experimental factors in evidence.

\section{Information Purchasing}

The major dependent variable in this study was the amount of information purchased by subjects in preparing for their self-presentation. Recall that the available information was of several types. To see whether the effects of impression type and self-monitoring differed for each type of information, an analysis of variance was carried out, with the level of self-monitoring and impression type as between-subjects factors and information type as a within-subjects factor with three levels: biographical, attitudinal, and personality characteristics. The results of the analysis support the hypotheses. Analysis of variance on the total amount of information purchased revealed a significant main effect for self- monitoring, $F(1,60)=10.65, p<.002$, a marginal main effect for impression type, $F(1$, $60)=3.57, p<.07$, and a significant twoway interaction between these factors, $F(1$, $60)=4.25, p<.05$. The marginal values of Table 1 provide the means for each cell of the design. High self-monitoring subjects purchased more information than low self-monitoring subjects. Fabricating subjects showed a tendency to purchase more information than those conveying an accurate impression. High self-monitoring fabricators reliably bought more information than all others. ${ }^{3}$

An additional interesting finding was a three-way interaction between level of selfmonitoring, impression type, and information type, $F(2,120)=3.213, p<.05$. Inspection of the means (provided in Table 1 ) revealed the pattern of this interaction. For low selfmonitoring subjects, there were no differences in the amounts of information purchased. High self-monitoring subjects tended to buy the same amount of personality information, regardless of the truthfulness of the impression they were conveying; they tended to buy less biographical and attitudinal information when planning an accurate impression than when planning a fabrication.

It may be that, for the high self-monitors, what the other individual thinks she is like as a person is not differentially important in planning a performance. Personality characteristics are important elements of some baseline information about another, but they are probably not directly related to the issue at hand (at least not in this experiment). Personality information serves mainly to guide actors in choosing the general manner of selfpresentation (i.e., orientation to the other)

\footnotetext{
3 Inspection of the within-cell variances revealed that the assumption of homogeneity of variances was tenuous. The information purchased was transformed by the square root function, resulting in more homogenous cell variances. The analysis of variance for this transformed variable did not change the significance levels of any of the effects. Since the effects are more readily interpretable for the untransformed variable, results are discussed in terms of it. An analysis of variance was conducted using confederate as an additional between-subjects factor. Results showed no effects for confederate, alone or with any of the other factors.
} 
Table 1

Mean Number of Information Bits About the Partner Purchased by Actors as a Function of Impression Type, Level of Self-Monitoring, and Information Type

\begin{tabular}{|c|c|c|}
\hline \multirow{2}{*}{$\begin{array}{c}\text { Information } \\
\text { type }\end{array}$} & \multicolumn{2}{|c|}{ Impression type } \\
\hline & Accurate & Fabricated \\
\hline \multicolumn{3}{|c|}{ High self-monitoring } \\
\hline \multicolumn{3}{|l|}{ Attitudinal } \\
\hline$M$ & $.375_{\mathrm{a}}$ & $1.938_{b}$ \\
\hline$S D$ & .719 & 2.744 \\
\hline \multicolumn{3}{|l|}{ Biographical } \\
\hline$M$ & $.625_{\mathfrak{a}}$ & $1.875_{\mathrm{b}}$ \\
\hline$S D$ & 1.258 & 1.821 \\
\hline \multicolumn{3}{|l|}{ Personality } \\
\hline$M$ & $1.125_{\mathrm{a}}$ & $1.188_{\mathrm{ab}}$ \\
\hline$S D$ & 1.360 & 1.424 \\
\hline \multicolumn{3}{|l|}{ Total } \\
\hline$M$ & 2.125 & 5.000 \\
\hline$S D$ & 2.872 & 4.502 \\
\hline \multicolumn{3}{|c|}{ Low self-monitoring } \\
\hline \multicolumn{3}{|l|}{ Attitudinal } \\
\hline$M$ & $.438_{\mathrm{a}}$ & $.250_{\mathrm{a}}$ \\
\hline$S D$ & .629 & .683 \\
\hline \multicolumn{3}{|l|}{ Biographical } \\
\hline$M$ & $.438_{\mathrm{a}}$ & $.438_{\mathrm{a}}$ \\
\hline$S D$ & .629 & .727 \\
\hline \multicolumn{3}{|l|}{ Personality } \\
\hline$M$ & $.375_{\mathrm{a}}$ & $.438_{\mathrm{a}}$ \\
\hline$S D$ & .619 & .629 \\
\hline \multicolumn{3}{|l|}{ Total } \\
\hline$M$ & 1.250 & 1.125 \\
\hline$S D$ & 1.612 & 1.668 \\
\hline
\end{tabular}

Note. Means that do not share a subscript differ from each other at the .05 level of significance by the Newman-Keuls procedure.

and not specific elements of the performance. Therefore, personality information is equally important in conveying an accurate or a fabricated impression.

Attitudinal and biographical information is more directly related to the issue at hand. These data give indications of how one might feel about the issue around which the impression is being built. This would be especially important for a fabrication. High self-monitoring actors in a fabrication are feeling their way through unfamiliar territory and need relevant information about their partners. With an accurate impression, high self-monitors can rely on their abilities as performers. The luxury of being themselves may lend high self-monitors the confidence to do without this information and deal with contingencies as they arise. In short, a fabricated impression is more of a challenge to high self-monitoring actors than is an accurate impression. ${ }^{4}$

One might ask if the difference between high and low self-monitors was due to the fact that low self-monitoring actors felt no heightened concern when contemplating a fabrication. Although no data from this experiment directly addressed this question, some indirect evidence suggests that this was not the case. All subjects judged the accurate performance as easier $(M=3.97)$ than the fabricated one $(M=1.87), F(1,60)=12.53, p<.001$, and there were no such differences between high and low self-monitors, $F(1,60)<1$. It is probable that all subjects anticipated difficulty with a fabrication. Because low selfmonitors rely on their own internal states for resources, however, the challenge afforded by a fabrication did not motivate low self-monitoring actors to acquire more information about their partner.

\section{Reactions to the Performance}

The second set of hypotheses focused on the aftermath of the self-presentation. Actor subjects and observer confederates were given two sets of 15 bipolar items in semantic differential format to record their impressions following the encounter. Responses were made on a 9-point semantic differential scale. For purposes of analysis, a score of 9 was given to the positive extreme and 1 to the negative extreme.

It should be noted that confederate ob-

4 This explanation is entirely post hoc and should be taken with some caution. One factor that adds to the tentativeness of this reasoning is that for the low self-monitors, a floor effect is operating: They cannot buy fewer than zero pieces of information. However, tests for the differences between accurate and fabricated impression type were conducted within each level of information type using only high selfmonitors. In a test for "simple effects" of impression type (cf. Kirk, 1968, chap. 8), the results indicated significant differences $(p<.05)$ in the amount of biographical and attitudinal information purchased by accurate and fabricating subjects; there was no difference with respect to personality information. 
servers' ratings of the subjects' performance quality were their own personal judgments of what they saw; their ratings of the subjects' feelings during the interaction were what the subjects were apparently feeling, as revealed by their verbal and nonverbal behavior. Further, subjects and confederates completed these items while totally isolated from each other, with no way of influencing each other's ratings. Subjects were not told that they would be rating themselves until after the discussion was over, nor did they know that the confederate had rated them until the debriefing. Confederates were not told that the subjects had rated themselves until the last subject had been run. Finally, it should be recalled that the confederates were blind to all experimental conditions, so that any differences due to these factors must have been communicated through the performance.

Because of the large number of evaluations being made ( 30 each for subject and confederate), subjects' and confederates' ratings were factor analyzed separately using Rao's uniqueness rescaling procedure with varimax rotation. This served to organize the evaluations, reduce the number of analyses conducted, and ensure that the variables to be analyzed were relatively orthogonal.

Results for subjects' self-reports revealed three factors for the performance quality ratings and four factors for the feeling states ratings. For the performance quality items, Factor 1, an acting-quality factor, consisted of the items unconstrained-constrained, satisfied-dissatisfied, and graceful-awkward. The second factor reflected organization and included organized-disorganized, systematicunsystematic, clear-unclear, impressive-unimpressive. Factor 3 indicated communicative quality, with consistent-inconsistent, understood-misunderstood, and persuasive-unpersuasive loading on this factor.

For the feeling states items, the first factor seemed to reflect satisfaction with the performance: positive-negative, capable-incapable, satisfied-frustrated, commendable-reprehensible, and enthusiastic-apathetic. The second factor was a security factor: calmnervous, comfortable-uncomfortable, secureinsecure, and confident-unconfident. Factor 3 was a friendliness factor and consisted of friendly-unfriendly and likable-unlikable. Finally, Factor 4 seemed to reflect personal comportment: sensible-foolish, straightforward-devious, and free-constrained.

Turning to the confederates' evaluations of the subjects, four factors emerged from the ratings of performance quality. Factor 1 indicated performance competence: interestinguninteresting, impressive-unimpressive, successful-unsuccessful, satisfied-dissatisfied, and believable-unbelievable. The second factor involved aesthetic reactions to the performance and consisted of organized-disorganized, graceful-awkward, flawless-flawed, and systematic-unsystematic. Factor 3 involved communicative clarity, with understood-misunderstood and clear-unclear. Factor 4 reflected performance coherence: persuasive-unpersuasive and consistent-inconsistent.

For the feeling states items, five factors were discovered. Factor 1 consisted of items dealing with the actors' perceived comfort in the role: calm-nervous, comfortable-uncomfortable, and free-constrained. Items loading on Factor 2 suggested personal accomplishment: commendable-reprehensible and capable-incapable. Factor 3 involved security, with secure-insecure, unself-conscious-selfconscious, confident-unconfident, and satisfied-frustrated. The fourth factor indicated friendliness: likable-unlikable, friendly-unfriendly, and sensible-foolish. Finally, Factor 5 suggests role commitment: enthusiasticapathetic and positive-negative. ${ }^{.}$

A second-order factor analysis was run on

5 As the reader may have noted, the factor structures for the two rating sources (subject and confederate) are somewhat different. The difference appears to reflect the perspective each brings to the performance. The factor structure for the actor subjects indicates their concern for the technical qualities of the performance. By contrast, the factor structure for the confederates reveals their critical reactions to the aesthetics of the performance. Such a performer/audience difference in perspectives is consistent with the dramaturgical approach to social interaction. However, it should be noted that the experimental design may have contributed to this difference. The observers were confederates of the experimenter and as such may have felt more like an audience than a coparticipant in the interaction. 
the entire set of factors separately for subjects and confederates. ${ }^{6}$ Variables used in the second-order analysis were obtained by summing the scores for the items loading on the same factors. For the subjects, analysis of the seven first-order factors yielded three second-order factors. Factor 1 involved performance competence, performance satisfaction, security, and personal comportment (performance quality first-order Factor 1 and feeling states firstorder Factors 1, 2, and 4) and may be labeled a performance enactment factor. Factor 2 included organization and communicative quality (performance quality first-order Factors 2 and 3 ), which appears to deal with the mechanics of the performance. Factor 3 was the friendliness factor (feeling states firstorder Factor 3).

For the confederates' ratings, analysis of the nine first-order factors also produced three second-order factors. Factor 1 involved performance competence, performance aesthetics, communicative clarity, performance coherence, and personal accomplishment (all the performance quality first-order factors plus feeling state first-order Factor 2) and indicates a critical evaluation of the performance. Factor 2 included comfort in the role, security, and role commitment (feeling states firstorder Factors 1, 3, and 5), which appears to reflect a critical evaluation of the actors' personal fit to the role requirements. Finally, Factor 3 was the friendliness factor (feeling states first-order Factor 4 ).

Analysis of variance was conducted on the second-order factors. Variables were created by summing the scores for the items loading on the same factor. Results provide moderate support for the hypotheses. The subjects' second-order factors were relatively unaffected by the experimental conditions. No effects for level of self-monitoring achieved statistical significance. Impression type affected only the performance enactment factor (Factor 1). Subjects rated their performance enactment more positively for an accurate impression $(M=100.31)$ than for a fabrication ( $M=$ 88.44), $F(1,60)=6.64, p<.025$.

The experimental conditions had greater influence on the confederates' second-order factors. Level of self-monitoring affected all three factors. For the performance evaluation factor (Factor 1), confederates rated high self-monitors more favorably $(M=108.41)$ than low self-monitors $(M=93.72), F(1$, $60)=6.82, p<.025$. High self-monitors were also seen to fit the role they enacted (Factor 3 ) better than low self-monitors ( $M=65.59$ for high self-monitors vs. $M=59.53$ for low self-monitors), $\quad F(1,60)=3.97, \quad p<.06$. Finally, high self-monitors were seen as friendlier (Factor $3 ; M=23.62$ ) than low self-monitors $(M=22.19), F(1,60)=4.05$, $p<.05$, a result also reported in Lippa (1976).

Impression type influenced the confederates' ratings on two second-order factors. Accurate impression managers were judged by the confederates to fit the role (Factor 2) better $(M=65.69)$ than fabricators ( $M=$ $59.44), F(1,60)=4.22, p<.05$. In addition, they tended to see accurate impression managers as friendlier (Factor $3 ; M=23.59$ ) than fabricators $(M=22.22), F(1,60)=$ $3.71, p<.06$.

Although the targets seemed sensitive to many aspects of the actors' performances, one exception stands out. They did not seem to realize when the actors were deceiving them. Observers rated fabricators as no less straightforward or believable than accurate performers were. Believability was affected by the level of self-monitoring. High self-monitors were rated as more believable $(M=$ 7.47) than low self-monitors $(M=6.03)$, $F(1,60)=5.95, p<.02$.

Apparently, actors were able to look fairly convincing during the discussion. They did not

${ }^{6}$ A second-order factor analysis was conducted using all 16 factors extracted for both subjects and confederates. The results yielded 4 second-order factors. Factor 1 consisted of all the confederates' firstorder factors. Factors 2, 3, and 4 were identical to the 3 second-order factors reported in the analysis involving only the subjects' factors. Because there was no mixing of first-order factors across rating source in the second-order structure and because separate analyses of the subjects' and confederates' factors yielded identical results in the subjects' case and more differentiated results in the confederates' case, it was decided to use the second-order factors from the separate analyses as dependent variables in the analyses of variance. 
fool themselves, however. Actors in the fabricating condition reported themselves as less straightforward ( $M=5.94)$ than those conveying an accurate impression $(M=7.34)$, $F(1,60)=5.48, p<.05$, and slightly less believable $(M=7.09$ for fabrication vs. $M=$ 7.81 for accurate impression), $F(1,60)=$ $3.26, p<.08$.

Compare these results to those in Lippa (1976), in which subjects sequentially role played teachers as introverts, extraverts, and themselves. Although rating high self-monitors as more technically proficient actors, observers were better able to detect their true tendencies toward extraversion. The correlation between perceived and actual (as assessed by premeasures) extraversion was greater for high than for low self-monitors. In other words, high self-monitors were perceived more accurately than low self-monitors. Perhaps the difference is due to differences in the content of the selfpresentation. In the present study, attitudes were being conveyed; in Lippa's study, the content of the impression was a personality characteristic. Expressive control for the latter might be much more difficult.

\section{Conclusion}

The results of this study indicate that actors involved in planning a self-presentation exhibit differential interest in information about a prospective interaction partner. A person variable (self-monitoring) and a situation variable (impression type) combined interactively to influence the amount of information acquired by impression managers. Specifically, only high self-monitors who planned a fabrication tended to purchase information about their prospective partner. Further, whereas low self-monitors found all types of information unnecessary, high selfmonitoring actors placed different values on the kind of information available. High selfmonitors acquired personality information about their partner regardless of impression type but purchased attitudinal and biographical information only when planning a fabrication.

This study also investigated actors' and observers' reactions to the actors' perform- ance. One striking result is the degree to which subjects' self-reports were unaffected by the experimental conditions. In particular, high self-monitors rated themselves no better or worse than low self-monitors did. But confederates clearly distinguished between them, consistently evaluating high self-monitors more positively. This suggests that although high self-monitors may have been as worried as their low-scoring counterparts, they managed to hide those worries from their partner.

Several aspects of this experiment may limit the generalizability of the results. First, it may be that the results presented above apply only to those individuals whose true attitudes favor the issue involved in the performance. It should be recalled that all subjects were selected for their strong support for legalizing marijuana, a popular stand on college campuses. Perhaps the behavior of fabricating actors was due to being seen as supporting an unpopular position as much as to giving a deceptive performance.

Second, the impression to be conveyed was assigned by the experimenter and was not chosen by the actors themselves. It may be that the effects due to impression type were actually a function of a forced fabrication. Actors assigned a truly self-descriptive impression may behave no differently than they would if they had selected the impression themselves; actors assigned a fabrication may behave differently, more because they had no choice in the matter than because the impression was not honest. There are situations in which demands for a particular impression are strong enough so that very little choice exists. If the goals desired from the interaction are important, actors may be induced to enact the impression demanded by the situation, even if it involves a fabrication. Their plight would be not unlike that of fabricating subjects in the present experiment.

In sum, the results of this study suggest that impression managers are differentially concerned with acquiring information about another participant in an upcoming interaction. High self-monitors planning a fabrication are the only actors who acquire a significant amount of information about the other. More important, they will endure some personal 
costs to obtain this information. They apparently believe that the advantages of additional information in preparing a self-presentation outweigh the costs of obtaining it. In the present study, individuals acquired information without the other's knowledge. It would be interesting in future research to learn if high self-monitoring fabricators maintain their interest in purchasing information when the other knows what is being acquired and at what cost. Further insights into the planning of a self-presentation will provide greater understanding of the process guiding impression management.

\section{References}

Eiser, C., \& Eiser, J. R. Acquisition of information in children's bargaining. Journal of Personality and Social Psychology, 1976, 34, 796-804.

Eiser, J. R., \& Tajfel, H. Acquisition of information in dyadic interaction. Journal of Personality and Social Psychology, 1972, 23, 340-345.

Ekman, J., \& Friesen, W. V. Nonverbal leakage and clues to deception. Psychiatry, 1969, 32, 88-105.

Goffman, E. The presentation of self in everyday life. Garden City, N.J.: Doubleday, 1959.

Ickes, W., \& Barnes, R. D. The role of sex and selfmonitoring in unstructured dyadic interactions.
Journal of Personality and Social Psychology, 1977, 35, 315-330.

Kaplan, J, Marijuana: The new prohibition. New York: Meridian, 1970.

Kirk, R. E. Experimental design: Procedures for the behavioral sciences. Belmont, Calif.: Brooks/Cole, 1968.

Lippa, R. Expressive control and the leakage of dispositional introversion-extraversion during roleplayed teaching. Journal of Personality, 1976, 44, 541-559.

National Commission on Marijuana and Drug Abuse. Marijuana: A signal of misunderstanding (Appendix, Vol. 2). Washington, D.C.: U.S. Government Printing Office, 1972.

Snyder, M. Self-monitoring of expressive behavior. Journal of Personality and Social Psychology, 1974, 30, 526-537.

Snyder, M. Cognitive, behavioral, and interpersonal consequences of self-monitoring. In P. Pliner, $\mathbf{K} . \mathbf{R}$. Blankstein, I. M. Spigel, T. Alloway, \& L. Krames (Eds.), Advances in the study of communication and affect: Vol. 5. Perception of emotion in self and others. New York: Plenum Press, 1978.

Snyder, M. Self-monitoring processes. In L. Berkowitz (Ed.), Advances in experimental social psychology (Vol. 12). New York: Academic Press, in press.

Weiler, J., \& Weinstein, E. A. Honesty, fabrication, and the enhancement of credibility. Sociometry, $1972,35,316-331$.

Received July 10, 1978 